\title{
Flexural and Shear Behavior of FRP Strengthened AASHTO Type Concrete Bridge Girders
}

\author{
Nur Yazdani, ${ }^{1}$ Farzia Haque, ${ }^{2}$ and Istiaque Hasan ${ }^{3}$ \\ ${ }^{1}$ Civil Engineering Department, University of Texas at Arlington, Arlington, TX, USA \\ ${ }^{2}$ Bridge Division, Texas Department of Transportation, Dallas District, Dallas, TX, USA \\ ${ }^{3}$ Pennoni Associates, Philadelphia, PA, USA
}

Correspondence should be addressed to Nur Yazdani; yazdani@uta.edu

Received 29 July 2016; Accepted 19 October 2016

Academic Editor: Claudio Mazzotti

Copyright (C) 2016 Nur Yazdani et al. This is an open access article distributed under the Creative Commons Attribution License, which permits unrestricted use, distribution, and reproduction in any medium, provided the original work is properly cited.

\begin{abstract}
Fiber-reinforced polymers (FRP) are being increasingly used for the repair and strengthening of deteriorated or unsafe concrete structures, including structurally deficient concrete highway bridges. The behavior of FRP strengthened concrete bridge girders, including failure modes, failure loads, and deflections, can be determined using an analytical finite element modeling approach, as outlined in this paper. The differences in flexural versus shear FRP strengthening and comparison with available design guidelines are also beneficial to design professionals. In this paper, a common AASHTO type prestressed concrete bridge girder with FRP wrapping was analyzed using the ANSYS FEM software and the ACI analytical approach. Both flexural and shear FRP applications, including vertical and inclined shear strengthening, were examined. Results showed that FRP wrapping can significantly benefit concrete bridge girders in terms of flexure/shear capacity increase, deflection reduction, and crack control. The FRP strength was underutilized in the section selected herein, which could be addressed through decrease of the amount of FRP and prestressing steel used, thereby increasing the section ductility. The ACI approach produced comparable results to the FEM and can be effectively and conveniently used in design.
\end{abstract}

\section{Introduction}

Fiber-reinforced polymers (FRP) are recent innovations in structural engineering, as compared to concrete, steel, and wood. These materials have certain advantages over the traditional materials, such as high stiffness-to-weight and strength-to-weight ratios, corrosion resistance, and constructability. Civil engineering applications of FRP sheets include rehabilitation or restoration of the strength of a deteriorated structural member, retrofitting or strengthening a sound structural member to resist increased loads, and correction of design or construction errors. FRP wrapping is increasingly being used with structural members made of reinforced concrete, prestressed concrete, and masonry.

One area in which FRP sheets are being used quite frequently in recent years is the strengthening of structurally deficient or damaged concrete bridges. As is widely known, a significant percentage of the bridges in the US is structurally deficient. Deficiency in bridges can be caused by design flaws, deterioration due to environmental impact, increase in service loads, and accidental vehicular impacts [1]. Traditional techniques to strengthen structural members include externally bonded steel plates, steel or concrete jackets, and external posttensioning (ACI) [2]. Labor and equipment costs to install FRP systems are often lower than traditional techniques, and installation is easier in areas with limited access. FRP systems also provide better aesthetics in many cases.

FRP wrapping of concrete bridge girders and columns can improve flexural, shear, corrosion, seismic, and impact resistance (Figure 1). A state-of-the-art report by ACI Committee 440 [2] provides guidance for the selection, design, and installation of FRP wrapping systems for externally strengthening concrete structures, based on experimental research, analytical work, and field applications. The ACI report outlines design procedure for flexure, shear, and axial force and combined axial and bending forces, which are considered to be conservative. ACI 440 also mentions areas that 


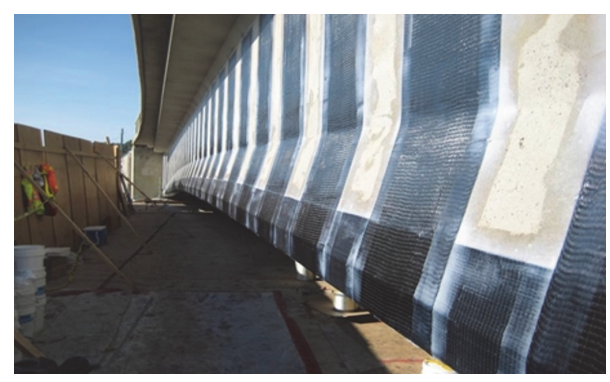

FIGURE 1: FRP Flexural and shear strengthening.

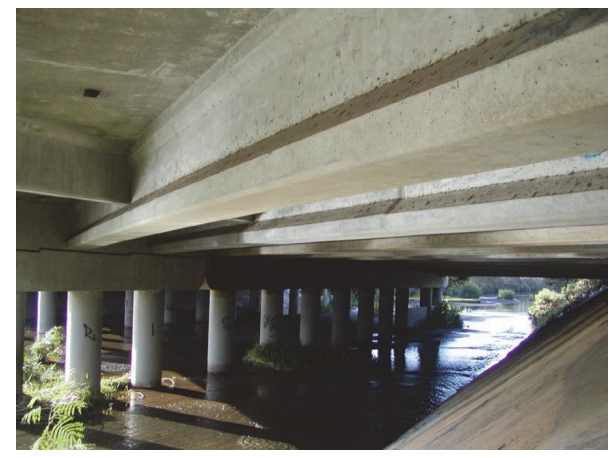

FIGURE 2: AASHTO type bridge girders with composite deck.

require additional research, including theoretical modeling of FRP strengthened structures. Besides experimental and field tests, finite element models (FEM) of FRP strengthened structural members are an alternate and economic avenue to determine their behavior.

The objective of this study [3] was to model a prestressed concrete AASHTO type IV bridge girder using the finite element software ANSYS [4], to analyze flexural and shear strengthening with FRP, and to compare the results obtained with ACI 440 provisions. AASHTO type IV bridge girders are popular for moderate spans (24 to $36 \mathrm{~m}$ ) and are widely used in the USA (Figure 2). This study provides important information on the FEM procedure for FRP strengthened prestressed concrete girders. The results obtained are very helpful to designers and researchers in understanding practical and cost-effective design procedure for flexure and shear strengthening of prestressed concrete bridge girders with FRP wrapping.

Experimental and analytical studies of Carbon FRP (CFRP) retrofitted prestressed concrete girders showed that the use of CFRP can result in increased moment and shear resisting capacities. Di Ludovico et al. [5] investigated five prestressed concrete I-shaped girders, which were designed according to ANAS (Italian Transportation Institute). One of them was undamaged, two of them were predamaged, and two of them were CFRP retrofitted. Four-point loading using two hydraulic jacks was applied up to theoretical yielding. It was suggested that fiber debonding between the girder and CFRP may take place in the undamaged girder, which has to be prevented to restore full flexural capacity. It was found that the U-shaped CFRP laminates experienced
$1 \%$ strain before debonding. Cementitious mortar had to be placed between concrete and the repair zone to ensure perfect bonding. Both stiffness and flexural moment capacity of girders increased due to CFRP wrapping. Cerullo et al. [6] conducted an investigation on a real decommissioned bridge girder repaired with externally bonded CFRP. Repair of one AASHTO type III concrete girder was carried out from a damaged bridge. Before CFRP application, cracks on the damaged girder were mapped and flexural behavior was examined by elastic load test. The shear strength deficiency of the girder was found by investigating the crack pattern and spalling of concrete. Horizontal cracks, caused by flexural loading, could successfully be repaired using CFRP. The Canadian Standards Association (CSA) code was found to be conservative for design. The CFRP retrofitting took only three days, which was found to be very convenient. Petty et al. [7] tested eight simply supported I-shaped 42-yearold prestressed concrete bridge girders retrofitted with CFRP for ultimate shear capacity. A single concentrated load was applied near the critical shear load location. Only $54 \%$ of the tensile capacity of CFRP could be utilized due to the variation in cross section of the girder. The strut-and-tie model was found to be effective in predicting the shear capacity of the girders. The AASHTO LRFD method was found to be more accurate than the ACI approach for shear capacity prediction of bridge girders. The girder shear capacity increased by $36 \%$ due to the vertical U-shaped strips.

Several design guides, standards, and manufacture's guidelines are available worldwide for the design and analysis of FRP strengthening systems for concrete structures. Some of these provisions are based on theoretical models, while others are based on experimental work [8]. In the USA, the primary design/analysis source is the guidelines published by Committee 440 of the American Concrete Institute. In ACI 440, the design recommendations are based on limit state method and strength/serviceability requirements. Additional load factors are applied to the contribution of the FRP reinforcement. These factors were determined based on statistical evaluation of variability in mechanical properties, predicted versus full-scale test results, and field evaluations. The following failure modes are considered: (1) crushing of concrete before yielding of the reinforcing steel; (2) yielding of tension steel followed by rupture of the FRP laminate; (3) yielding of the tension steel followed by concrete crushing; (4) shear/tension delamination of the concrete cover; and (5) debonding of the FRP from the concrete substrate [8]. Although Mode 2 is preferred in order to fully utilize the strengths of both the prestressing steel and the FRP laminate, laboratory testing to date has only shown this mode as a possibility for beams with proper detailing. In most cases, Mode 4 has controlled the failures. Additional information on this failure mode is available in the literature [9-12].

\section{Materials and Methods}

ANSYS Parametric Design Language (APDL) 14.5 was used herein to model a typical AASHTO type IV I-girder. ANSYS is capable of predicting the nonlinear behavior of FRP 
strengthened prestressed girders. A simply supported typical interior girder with a span of $24 \mathrm{~m}$ was considered.

Three types of ANSYS elements were used in the model. The Solid 65 element was used to create 3D models of concrete. This element is capable of simulating concrete cracking in tension and crushing in compression. It has eight nodes and three degrees of freedom at each node: translations in the nodal $x, y$, and $z$ directions. This element is also capable of simulating plastic deformation and creep. Link 180 element (uniaxial tension-compression) was used to model the prestressing steel and shear reinforcements. It has two nodes with three degrees of freedom at each node: translations in the nodal $x, y$, and $z$ directions. This element is capable of rotation, large deflection, and large strain. FRP wrapping was modeled using the Shell 41 element. This element has four nodes and three degrees of freedom at each node: translations in the nodal $x, y$, and $z$ directions. Shell 41 is a 3D element having membrane stiffness but no bending stiffness and has variable thickness, stress stiffening, and large deflection options.

Four sets of FEM real constants (constitutive properties) were used. Set 1 for the Solid 65 elements had the smeared reinforcement material numbers, volume ratio, and orientation angle entered as zero, as reinforcement was modeled with Link 180 elements. Set 2 was used for the Link 180 element to represent longitudinal prestressing steel. Set 3 was used for Link 180 element to represent the stirrups, and Set 4 was used for Shell 41 elements to model the epoxy adhesive. Set 5 was used for the FRP modeling with Shell 41 elements. Other parameters, such as element $x$-axis rotation, elastic foundation stiffness, and added mass, were entered as zero, as they were not applicable for this model.

The material properties were defined by five models for concrete, mild steel rebar, prestressed steel, epoxy, and FRP. Parameters needed to define the material models are shown in Table 1.

Material Model \#1 was defined for concrete. The Solid 65 element requires linear isotropic and multilinear isotropic concrete material properties. The multilinear isotropic material uses the Von Mises failure criterion along with the Willam and Warnke [13] model to define the concrete failure. The concrete compressive uniaxial stress-strain relationship was obtained using the following equations from MacGregor [14]:

$$
\begin{aligned}
f & =\frac{E_{c} * \varepsilon}{1+\left(\varepsilon / \varepsilon^{\circ}\right)^{2}}, \\
\varepsilon^{\circ} & =\frac{2 f_{c}^{\prime}}{E_{c}}, \\
E_{c} & =\frac{f}{\varepsilon},
\end{aligned}
$$

where $E_{c}$ is modulus of elasticity; $f$ is stress at any strain $\varepsilon$; and $\varepsilon^{\circ}$ is strain at the ultimate compressive strength, $f_{c}^{\prime}$.

The multilinear relationship requires the first point of the curve to be defined by the user and satisfy Hooke's Law. The curve is used to help with convergence of the nonlinear solution algorithm. Figure 3(a) shows the concrete

\begin{tabular}{|c|c|}
\hline \multicolumn{2}{|c|}{ Model 1: concrete (linear and trilinear isotropic) } \\
\hline Density & $2400 \mathrm{~kg} / \mathrm{m}^{3}$ \\
\hline Modulus of elasticity & $34 \mathrm{GPa}$ \\
\hline Initial modulus of elasticity & $30 \mathrm{GPa}$ \\
\hline 28-day compressive strength & $48 \mathrm{MPa}$ \\
\hline Initial compressive strength & $34 \mathrm{MPa}$ \\
\hline Poisson's ratio & 0.2 \\
\hline Open crack shear transfer coefficient & 0.3 \\
\hline Closed crack shear transfer coefficient & 1 \\
\hline Uniaxial cracking stress & $4.33 \mathrm{MPa}$ \\
\hline Uniaxial crushing stress & -1 \\
\hline \multicolumn{2}{|c|}{ Model 2: shear steel (bilinear isotropic) } \\
\hline Modulus of elasticity & $199.9 \mathrm{GPa}$ \\
\hline Poisson's ratio & 0.3 \\
\hline Yield strength & $414 \mathrm{MPa}$ \\
\hline \multicolumn{2}{|c|}{ Model 3: prestressing steel (linear isotropic) } \\
\hline Modulus of elasticity & $193053 \mathrm{MPa}$ \\
\hline Ultimate tensile strength & $1862 \mathrm{MPa}$ \\
\hline Poisson's ratio & 0.3 \\
\hline \multicolumn{2}{|c|}{ Model 4: epoxy (linear isotropic) } \\
\hline Modulus of elasticity & $2758 \mathrm{MPa}$ \\
\hline Poisson's ratio & 0.4 \\
\hline \multicolumn{2}{|c|}{ Model 5: CFRP (linear orthotropic) } \\
\hline Modulus of elasticity (primary direction) & $62053 \mathrm{MPa}$ \\
\hline Other modulus of elasticity & $4826 \mathrm{MPa}$ \\
\hline Ultimate tensile strength & $931 \mathrm{MPa}$ \\
\hline Poisson's ratio & 0.22 \\
\hline Shear modulus & $3266 \mathrm{MPa}$ \\
\hline
\end{tabular}
stress-strain relationship, based on MacGregor [14]. Linearity
TABLE 1: Material models [9] and properties for FEM.

changes at $0.3 f_{c}^{\prime}$ and at a point defined by $f_{c}^{\prime}$ and $\varepsilon^{\circ}=0.003$, indicating traditional crushing strain for unconfined concrete. The intermediate points were calculated using (1). The shear transfer coefficients for open and closed cracks were determined using Wolanski [15] as a basis. The uniaxial cracking stress was based on the modulus of rupture, $f_{r}$, as shown in the following equation [16]:

$$
f_{r}=7.5 \sqrt{f_{c}^{\prime}} .
$$

The other variables in the concrete model were left to default.

Vertical or inclined U-stirrups of $9.5 \mathrm{~mm}$ diameter were spaced at $457 \mathrm{~mm}$ center throughout the span. Material Model \#2 for shear steel was bilinear isotropic, requiring the yield stress and the tangent modulus of the steel to be defined (Table 1). The prestressing steel consisted of 28 tendons that were $12 \mathrm{~mm}$ in diameter. The tendons were arranged in two layers in the bottom flange of the girder, as shown in Figure 4(a). They were lumped and modeled as concentrated at the center of the 28 tendons, connecting the nodes at $127 \mathrm{~mm}$ from the bottom surface of the girder. Material Model \#3 for prestressing steel, as shown in Figure 3(b), was 


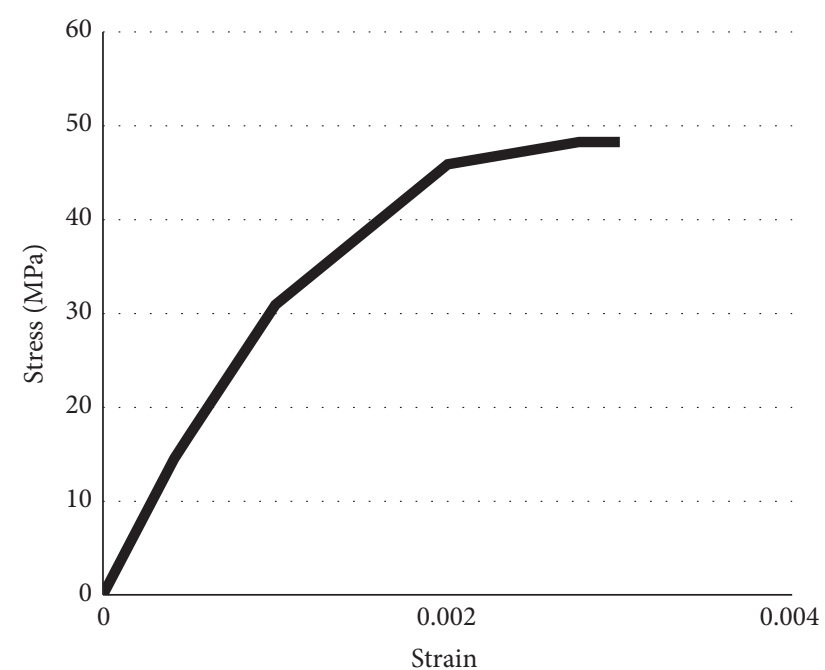

(a) Concrete

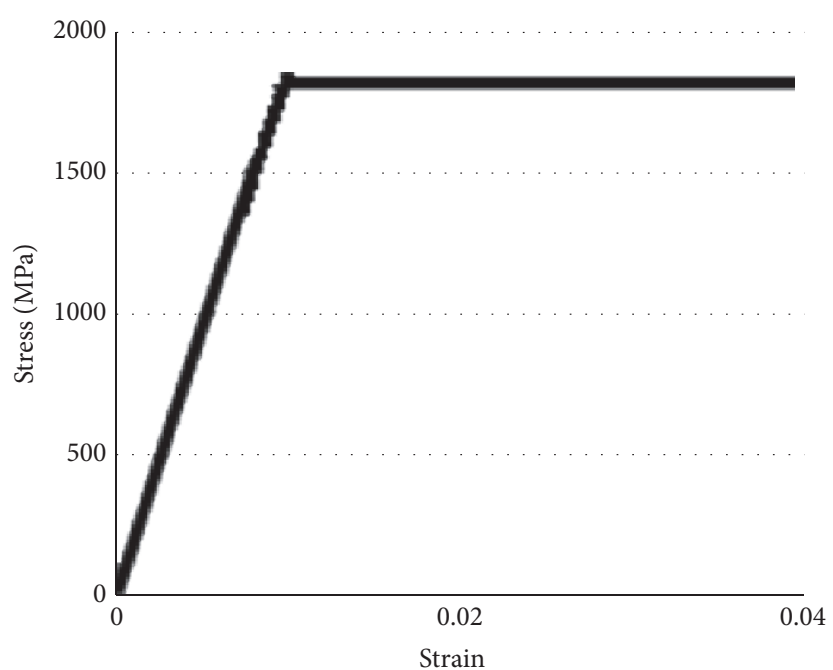

(b) Prestressing steel

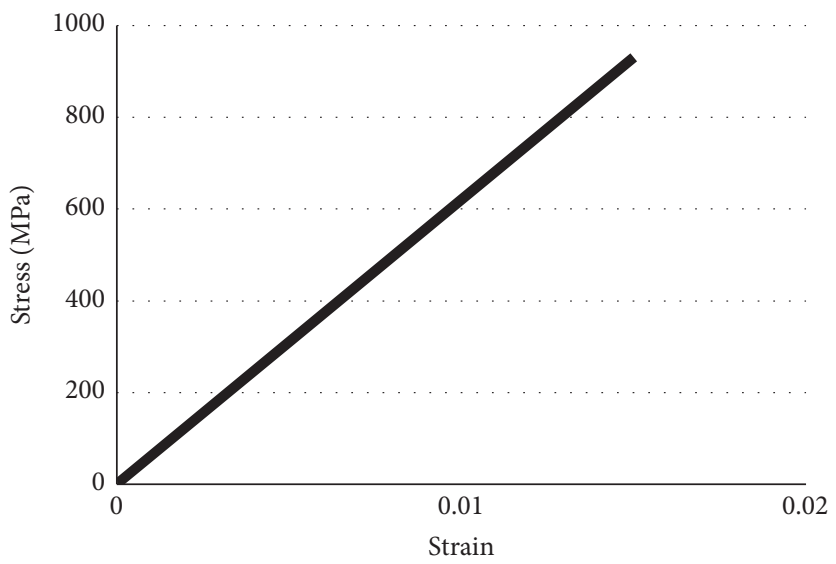

(c) FRP

FIgURE 3: Material stress-strain curves for FEM.

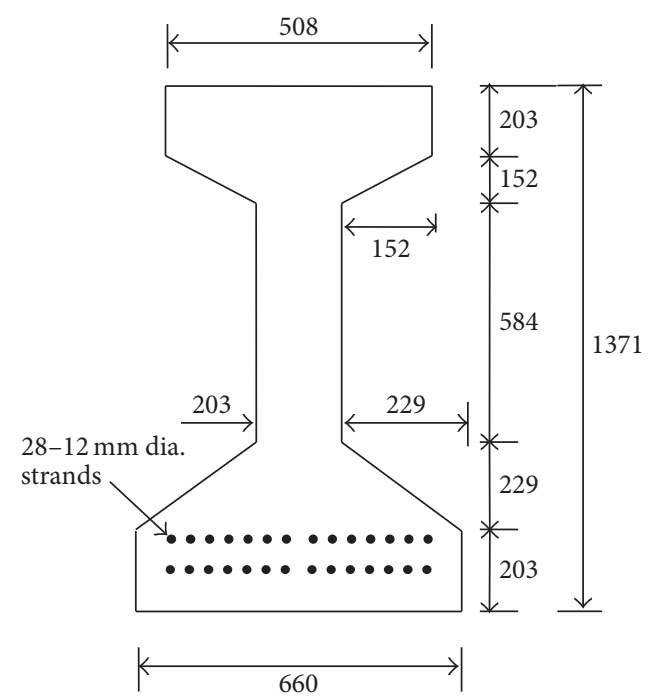

(a) Actual

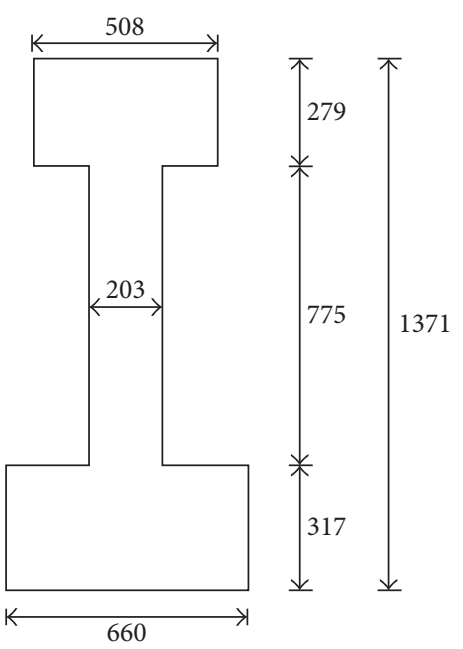

(b) Modified

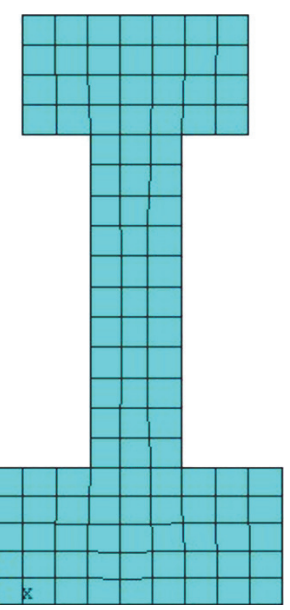

(c) Meshed

Figure 4: Girder cross sections (mm). 


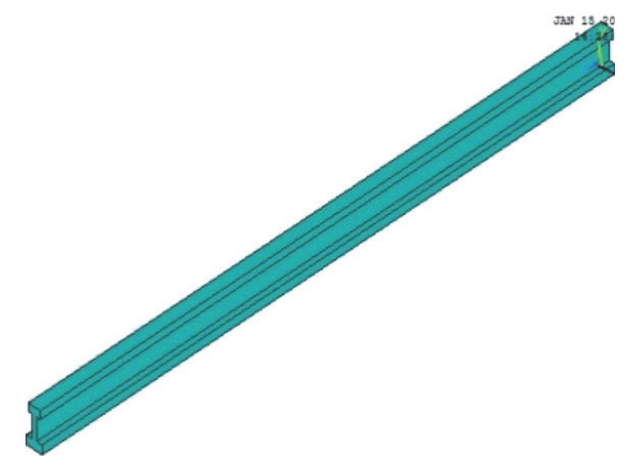

(a) Concrete

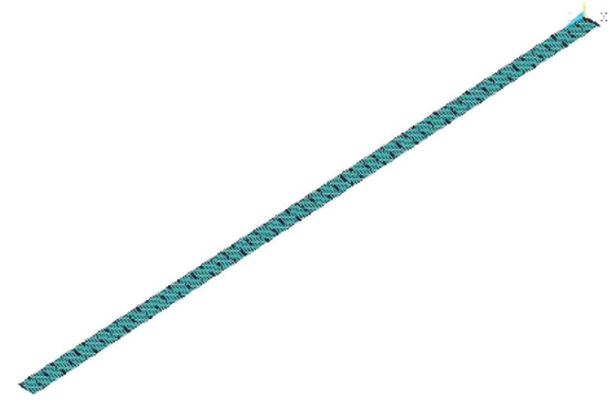

(c) Flexural FRP

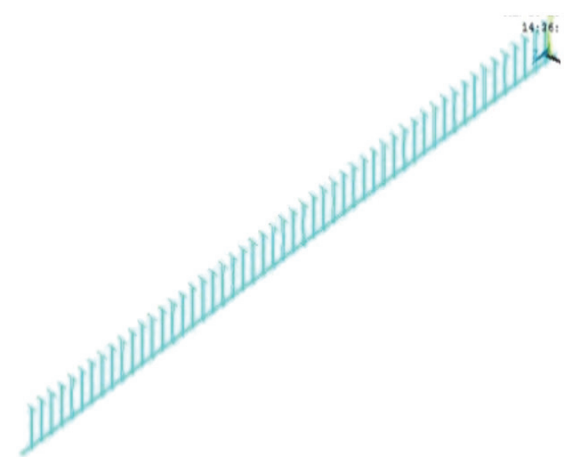

(b) Stirrup and prestressing steel

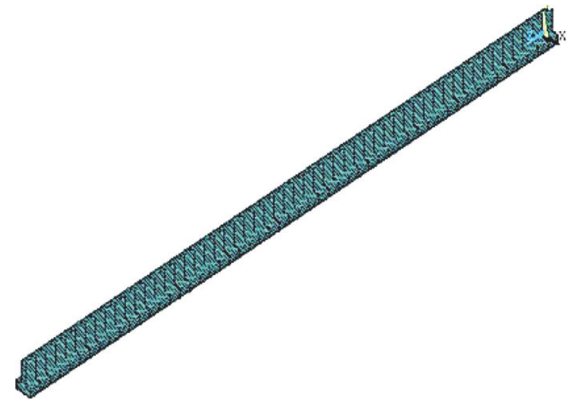

(d) Shear FRP

FIGURE 5: Concrete, steel, and FRP models.

multilinear isotropic following the Von Mises failure criteria, using the following [15]:

$$
\begin{aligned}
\varepsilon_{p s} & \leq 0.008 \\
f_{p s} & =193053 \varepsilon_{p s}(\mathrm{MPa}), \\
\varepsilon_{p s} & >0.008 \\
f_{p s} & =\left[268-\frac{0.075}{\varepsilon_{p s}-0.0065}\right] \times 0.1450377 \\
& <0.98 f_{p u}(\mathrm{MPa}),
\end{aligned}
$$

where $\varepsilon_{p s}$ is strain in prestressing steel and $f_{p s}$ is stress in prestressing steel.

The assumed thickness of epoxy adhesive was $0.51 \mathrm{~mm}$. Material Model \#4 for the epoxy was linear isotropic (Table 1). The one-layer CFRP sheet thickness was assumed as $1 \mathrm{~mm}$ and was represented with Model $\# 5$ with linear orthotropic properties, as shown in Figure 3(c). The assumed values for the CFRP and epoxy are common and can be found at manufacturer's websites.

AASHTO type IV girder section is not quite adaptable for FEM meshing and reinforcement modeling. Therefore, some conversion was made with the converted shape having the same area and height as the original girder and almost the same moment of inertia. Figure 4 shows the actual, converted, and FEM meshed girder sections, and Table 2 shows the comparison of the cross-sectional properties. The area was meshed with $76 \mathrm{~mm}$ mesh size, based on the nodes needed
TABLE 2: Original and transformed girder sections.

\begin{tabular}{lcc}
\hline & Original & Transformed \\
\hline Area, $\mathrm{mm}^{2}$ & 709031 & 709031 \\
Gross moment of inertia, $\mathrm{m}^{4}$ & 0.1085 & 0.1094 \\
Distance to centroid from top, $\mathrm{mm}$ & 628 & 627 \\
Height, mm & 1300 & 1300 \\
\hline
\end{tabular}

to model reinforcement and the aspect ratio for the elements. The meshed area with 140 nodes was extruded for the $24 \mathrm{~m}$ span length, as shown in Figure 5(a). The volume was divided into 53 elements along the longitudinal direction to allow for modeling of the stirrups. The prestressing steel model is shown in Figure 5(b). A two-layered section was used for the epoxy and FRP models (Figures 5(c) and 5(d)).

Five different girders with FRP and load configurations were investigated herein through separate modeling. Configurations 1 and 2 (controls) were girders without any FRP application and flexural or shear failure mode, respectively. Configuration 3 assumed one layer of FRP for flexural strengthening throughout the bottom of the girder bottom flange. Configuration 4 for shear strengthening involved vertical U-wrap FRP throughout the girder span, while Configuration 5 had U-wrap FRP as 45-degree inclined strips throughout the span. The shear cracks in beams are developed by diagonal tension. Therefore, it is expected that the 45degree U-wraps will be more efficient in arresting the shear cracks as the orientation of the fiber is perpendicular to the crack in this configuration. 


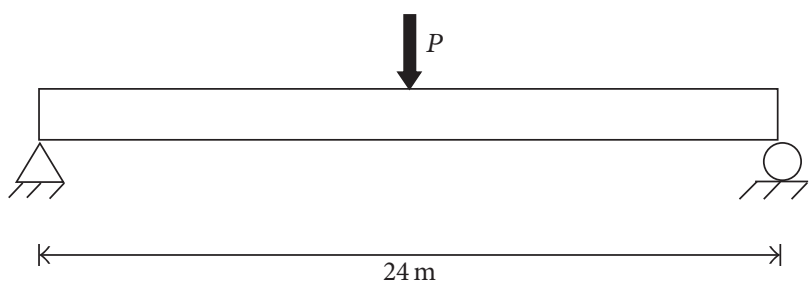

(a) Flexural load

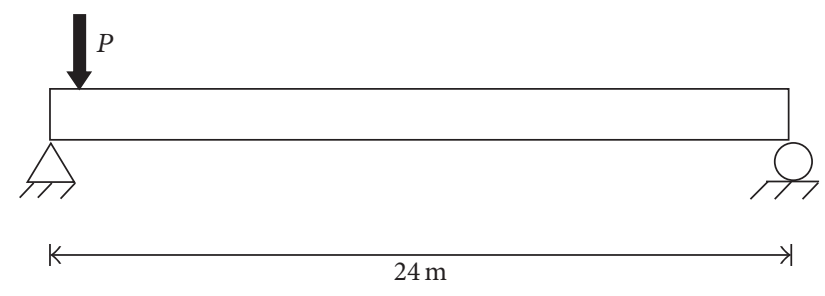

(b) Shear load

FIGURE 6: Load configurations on span.

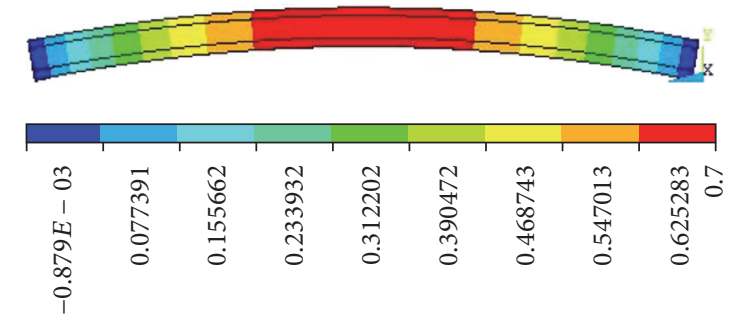

FIGURE 7: Camber due to prestress: flexural strengthening.

For the FRP strengthened and control girders, the flexural and shear designs were based on the AASHTO LRFD Bridge Specifications [17] and ACI 440 provisions [2].

2.1. Nonlinear Analysis. The $24 \mathrm{~m}$ simple span was simulated with a three-point loading setup. For Configurations 1 and 3, the point load was applied at mid-span for maximum bending moment effect, as shown in Figure 6(a). For Configurations 2, 4, and 5, the point load was applied adjacent to the support for maximum shear force effect (Figure 6(b)). A static analysis approach was utilized herein, with simple support displacement constraints provided at the nodes at the two ends. In the first load step, only initial prestrain was applied. Prestressing was defined using ANSYS Command Window [4]. The initial strain was determined from the effective prestress and the modulus of elasticity of prestressing steel. The applied prestress was $690 \mathrm{MPa}$, selected herein to facilitate convergence. The camber of the model girder due to prestress is shown in Figure 7. In the second load step, the self-weight of the girder was applied. The FEM was set up to examine three different girder behaviors: initial cracking, yielding of the prestressing steel, and flexural/shear failure of the girder. The FRP strengthened beam design was developed in order to avoid the Mode 4 [2] cover delamination failure in order to concentrate on fully achieving the tensile strength of the FRP composite fabric.

2.2. Analytical Calculations. Hand calculation was used herein to determine the expected theoretical capacities of the girders. The analysis is based on the steel and concrete strengths and the cross-sectional properties and steel layout (both prestressed and regular). Provisions from the AASHTO LRFD were utilized for the strength analysis of the control girder [17, Chapter 5]. AASHTO LRFD Specifications

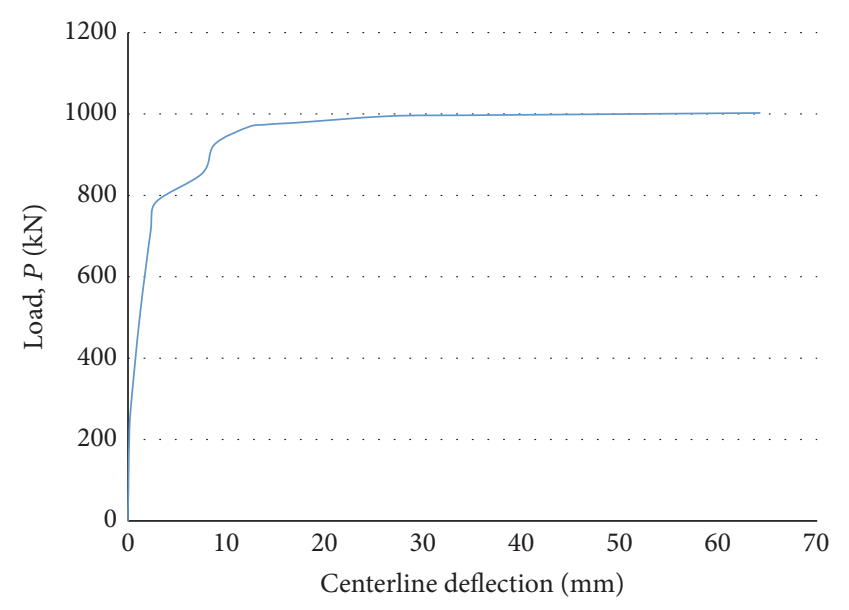

FIGURE 8: Load-deflection curve for control unstrengthened girder.

currently do not include provisions for the strength determination of FRP strengthened bridge members. Therefore, provisions from the ACI 440 guidelines were used to calculate flexural strengths for the FRP-reinforced girders [2, Chapter 10]. No load factors or resistance factors were applied. Based on the theoretical flexural capacities, equivalent three-point concentrated loads (Figure 6) were calculated from statics. The analytical and FEM load capacities for each girder are compared in Section 3.

\section{Results and Discussion}

FEM results are presented herein in the form of the values of the equivalent concentrated applied load corresponding to the various loading stages.

3.1. Unstrengthened (Control) Girder for Flexure (Configuration 1). The flexural load-deflection curve for the control girder showed seven distinct points: effective prestress, addition of self-weight, zero deflection, decompression, initial cracking, steel yielding, and failure (Figure 8). Hand calculations were used herein to validate the FEM results herein, as shown in Table 3. Initial prestress application stage, initial flexural cracks, cracking at yielding load, and cracking at flexural capacity are shown in Figure 9. Nonconvergence of the nonlinear algorithm occurred at a load of $1003 \mathrm{kN}$, indicating flexural failure. The excessive cracking that occurred 


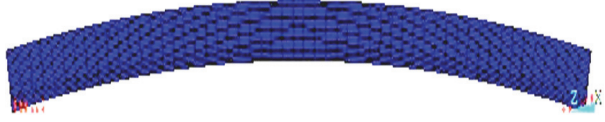

(a) Prestress and self-weight

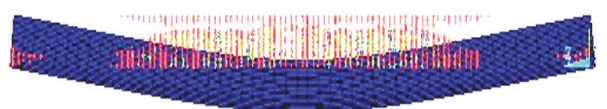

(c) At prestress yielding

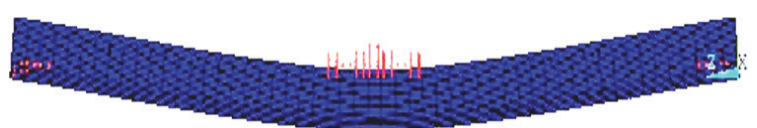

(b) Initial cracking

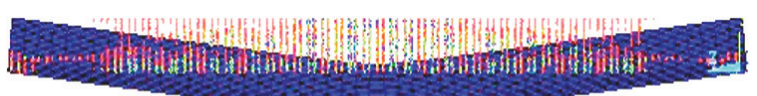

(d) At flexural capacity

FIGURE 9: Cracking stages: control girder.

TABLE 3: Flexural FEM and hand calculation results: control girder.

\begin{tabular}{lcc}
\hline Parameter & FEM & Hand calculations \\
\hline $\begin{array}{l}\text { Deflection due to } \\
\text { prestress, mm }\end{array}$ & -18 & -18 \\
$\begin{array}{l}\text { Deflection at } \\
\text { application of } \\
\text { self-weight, mm }\end{array}$ & -3.5 & -4.0 \\
$\begin{array}{l}\text { Zero deflection } \\
\text { load, kN }\end{array}$ & 44.5 & 51.0 \\
$\begin{array}{l}\text { Decompression } \\
\text { load, kN } \\
\begin{array}{l}\text { Initial cracking } \\
\text { load, kN }\end{array}\end{array}$ & 113 \\
$\begin{array}{l}\text { Failure load, kN } \\
\text { Failure stress in } \\
\text { prestressing steel, }\end{array}$ & 242 & 241 \\
MPa & 1003 & 897 \\
\hline
\end{tabular}

at this load stage throughout the entire span is evident in Figure 9(c). The FEM was validated by comparing various parameters with hand calculations and strain compatibility approach. Table 3 shows sample calculations for Configuration 1 girder. The corresponding loads and deflections values were close in general, validating the results from the FEM.

3.2. Flexural Strengthening (Configuration 3). In the flexural FEM, the point load was applied at mid-span, as shown in Figure 6(a). The load-deflection curve for this girder is shown in Figure 10, and various cracking stages are shown in Figure 11. The cracking, yielding, and flexural failure loads increased by $17.65 \%, 5.14 \%$, and $38 \%$, respectively, due to FRP flexural strengthening, as compared to the control unstrengthened girder (Table 4). The maximum deflection at the failure load decreased by $35 \%$ due to FRP wrapping, and localized cracking at the girder ends due to the fact that prestress was reduced. The height of the flexural cracks and the area of concrete subjected to flexural cracks also diminished, as compared to the control girder.

The analytical procedure from ACI 440-2R [2] was used herein to predict the flexural capacity of the strengthened girder, corresponding well with the FEM prediction. The detailed equations are quite few and are readily available from the reference. The ACI 440 prediction was close to that from

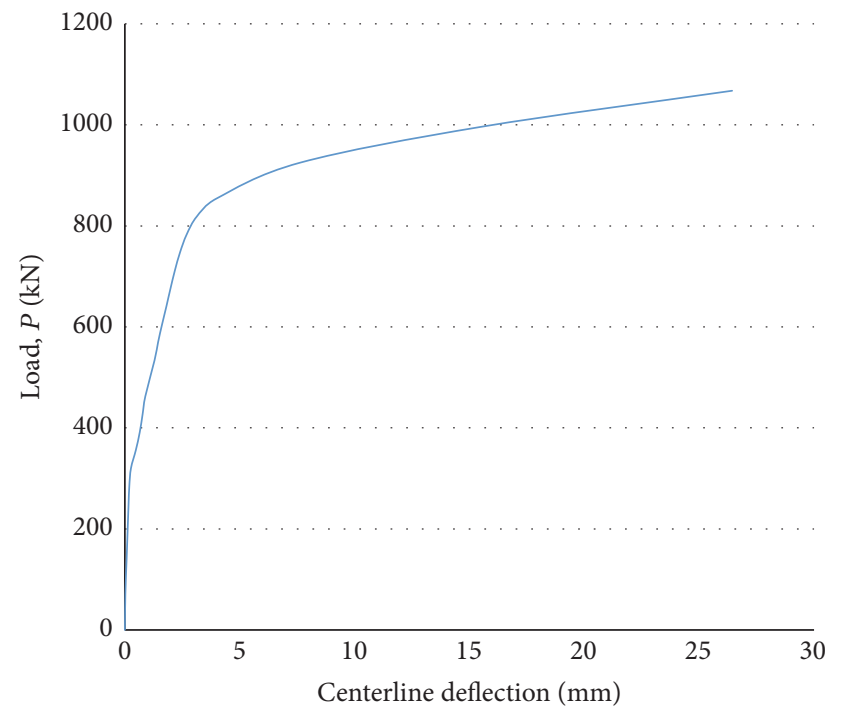

FIGURE 10: Load-deflection curve for flexurally strengthened girder.

the FEM. The effective failure strain prediction from ACI 440 was 0.008786 , again close to the FEM output, as was the maximum FRP stress (Table 4). The flexural failure mode of the girder was governed by yielding of the prestressing steel, followed by concrete crushing and FRP rupture, as per the FEM and ACI 440. This may be inferred from the fact that the tensile strength of the FRP $(931 \mathrm{MPa})$ was greater than the actual failure stress in the FRP (531 MPa). FRP strengthening caused $38 \%$ and $24 \%$ increases in the flexural load capacity of the girder, according to the FEM and the ACI 440 approach, respectively.

3.3. Shear Strengthening (Configurations 2, 4, and 5). For the shear strengthening configurations, the point load in the FEM was applied at $1.07 \mathrm{~m}$ (critical shear location according to AASHTO) from the girder end at one side (Figure 6(b)) to provide critical shear force effect on the girder. The loaddisplacement curve is presented in Figure 12, and pertinent results are presented in Table 5. Because of the low maximum bending moment near mid-span due to mostly self-weight, flexural failure did not control over shear failure in this FEM. The crack progression in the shear strengthened girders showed reduction in the height of the shear cracks, as compared to the control girder. The ultimate shear capacity 


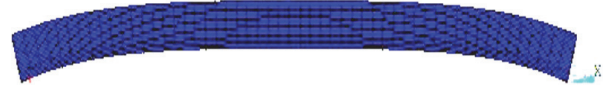

(a) Prestress and self-weight

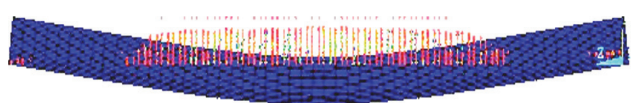

(c) At prestress yielding

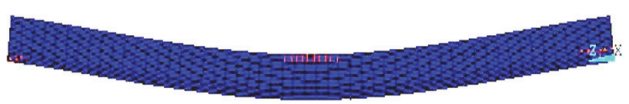

(b) Initial cracking

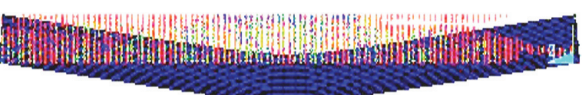

(d) At capacity

FIGURE 11: Cracking stages: flexurally strengthened girder.

TABLE 4: Flexural strengthening results.

\begin{tabular}{lccc}
\hline Load levels & $\begin{array}{c}\text { FEM outputs } \\
\text { Control girder }\end{array}$ & Strengthened girder & ACI 440 predictions \\
\hline Cracking load, $\mathrm{kN}$ & 242 & 284 & N/A \\
Yielding load, kN & 778 & 818 & N/A \\
Failure load, $\mathrm{kN}$ & 1003 & 1387 & 1248 \\
Deflection at cracking, mm & 15.5 & 19.3 & N/A \\
Deflection at flexural failure, mm & 27.9 & 18.1 & N/A \\
FRP strain at flexural failure & N/A & 0.0095 & 0.0088 \\
Maximum FRP stress, MPa & N/A & 531 & 545 \\
\hline
\end{tabular}

TABLE 5: Shear strengthening results.

\begin{tabular}{lccccc}
\hline & \multirow{2}{*}{ Control girder } & \multicolumn{2}{c}{ Strengthened girder (vertical FRP wrap) } & \multicolumn{2}{c}{ Strengthened girder (45 FRP wrap) } \\
& & FEM & ACI 440 & FEM & ACI 440 \\
\hline Failure load, kN & 1227 & 1575 & 1795 & 1968 & 2207 \\
FRP strain at failure & N/A & 0.0018 & 0.002 & 0.002 & 0.002 \\
\hline
\end{tabular}

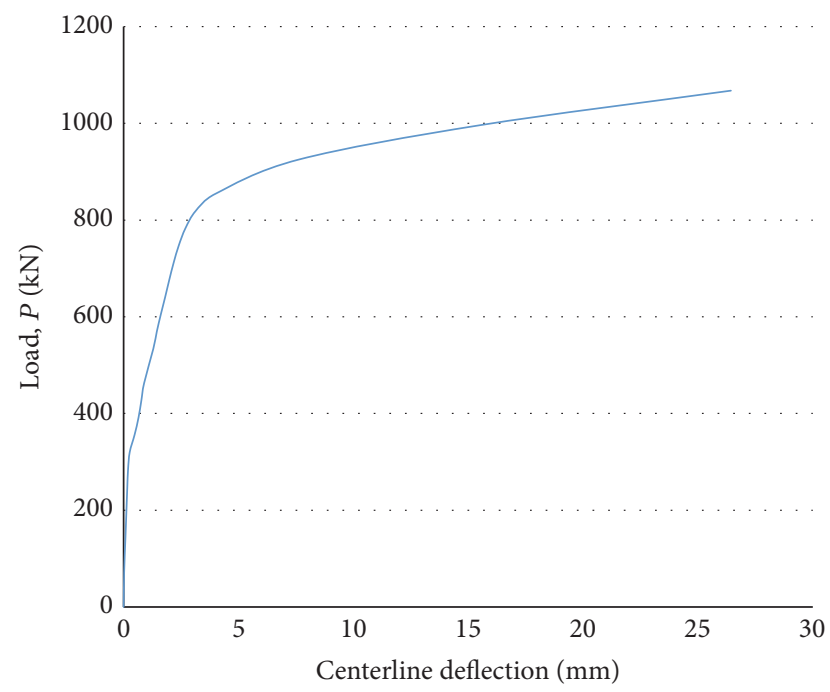

FIGURE 12: Load-deflection curve for shear strengthened girder.

of the vertical U-wrapped FRP strengthened girder was about $15 \%$ greater from the ACI 440 provisions, as compared to the FEM results. The FEM stress in the prestressing steel at failure was $435 \mathrm{MPa}$, much below the yielding capacity, as expected in a shear failure situation. The maximum vertical U-wrap FRP strain at failure was 0.0018 from the FEM and 0.002 from ACI 440 calculations, again showing that the shear failure was caused by stirrup yielding and not FRP rupture. The shear load capacity increased by about $13 \%$ due to the vertical wrapping. The ACI 440 shear capacity prediction was about $14 \%$ greater than the FEM output.

The influence of a 45-degree shear U-wrap FRP on the girder capacity is also presented in Table 5. The shear failure load capacity of the girder with the inclined FRP orientation increased by about $25 \%$ over that from the vertical orientation, and about $38 \%$ over the control girder shear capacity.

It is noted that $57 \%$ of the FRP tensile strength was used in flexural strengthening, while $74 \%$ was used in case of shear strengthening. This is because the FRP rupture mode did not control the girder failures herein, and the FRP strength was not fully utilized. FRP application reduced concrete cracking and girder deflection.

FRP strengthening effectively increased the girder load carrying capacity and reduced cracking and deflections. The prestressing steel strain at the nominal strength should be checked to maintain sufficient degree of ductility, according to ACI 440 [2]. Adequate ductility is achieved if the strain in the prestressing steel at the nominal strength is at least 0.013 , a bit higher than 0.011 from the FEM for flexural strengthening. To address this, the flexural strength reduction factor has to be decreased to 0.77 in design, according to ACI 440. To increase the girder ductility, the prestressing steel and the FRP 
areas could be reduced compared to the levels used in this study.

\section{Conclusions}

The following conclusions may be made based on the results from this study:

(1) An AASHTO type IV prestressed concrete bridge girder was successfully modeled using finite element software ANSYS for both flexural and shear FRP strengthening. The approach is simpler and more economic than full scale experimental testing.

(2) The FEM results are accurate, based on the validation of the results with hand calculations. Validation parameters included camber due to the initial prestress and after application of the self-weight of the girder, zero deflection, decompression, initial cracking, and failure loads.

(3) Excellent contributions from the FRP flexural strengthening to the bridge girder were evident for cracking, yielding, and flexural capacity loads. The flexural failure load increased by almost $38 \%$ due to FRP wrapping, and the maximum deflection decreased by $35 \%$. Tension cracks at the girder ends reduced due to FRP, and the height/extent of flexural cracks diminished.

(4) The analytical procedure from ACI 440 [2] yielded comparable results to the FEM output for flexural FRP strengthening in terms of the FRP strain, FRP stress, and failure load. The ACI 440 predictions were slightly conservative, as compared to the FEM results.

(5) Prestress steel yielding was the dominant failure mode for both the ACI 440 and FEM simulations, followed by concrete crushing. About $57 \%$ of the FRP tensile strength was utilized at flexural failure. The amounts of FRP and prestressing steel could be decreased within the design constraints to increase the prestressing steel strain and girder ductility.

(6) The FRP shear wrapping also contributed well to the girder shear capacity. The FEM results showed that the shear capacity increased by about $13 \%$ due to vertical shear wrapping and $38 \%$ due to inclined shear wrapping, respectively. The prestressing steel stress was well below yielding at failure, as expected.

(7) The yielding of stirrups was the dominant failure mode in shear, as demonstrated by both the FEM and the ACI 440 outputs. The ACI 440 provisions, however, were found to be a bit on the nonconservative side for shear strengthening, as compared to the FEM outputs. The FRP strains at failure from the two approaches were comparable.

(8) Both FEM and ACI 440 analytical techniques may be effectively used to predict the flexural and shear behavior of CFRP strengthened AASHTO type bridge girders.

\section{Competing Interests}

The authors declare that there are no competing interests regarding the publication of this paper.

\section{References}

[1] D. A. Brighton, Finite element analysis of an intentionally damaged prestressed reinforced concrete beam repaired with carbon fiber reinforced polymers [M.S. thesis], University of Toledo, 2011.

[2] ACI (American Concrete Institute) Committee 440, "Guide for the design and construction of externally bonded FRP systems for strengthening concrete structures," ACI 440.2R-08, ACI (American Concrete Institute), Farmington Hills, Mich, USA, 2008.

[3] F. Haque, Enhancing effectiveness of AASHTO type prestressed concrete bridge girder through fiber reinforced polymer strengthening [M.S. thesis], University of Texas at Arlington, Arlington, Tex, USA, 2014.

[4] ANSYS, ANSYS Parametric Design Language (Version 14.5), ANSYS, Canonsburg, Pa, USA, 2012.

[5] M. Di Ludovico, A. Prota, G. Manfredi, and E. Cosenza, "FRP strengthening of full-scale PC girders," Journal of Composites for Construction, vol. 14, no. 5, pp. 510-520, 2010.

[6] D. Cerullo, K. Sennah, H. Azimi, C. Lam, A. Fam, and B. Tharmabala, "Experimental study on full-scale pretensioned bridge girder damaged by vehicle impact and repaired with fiber-reinforced polymer technology," Journal of Composites for Construction, vol. 17, no. 5, pp. 662-672, 2013.

[7] D. A. Petty, P. J. Barr, G. P. Osborn, M. W. Halling, and T. R. Brackus, "Carbon fiber shear retrofit of forty-two-yearold AASHTO I-shaped girders," Journal of Composites for Construction, vol. 15, no. 5, pp. 773-781, 2011.

[8] M. Mohanamurthy and N. Yazdani, "Flexural strength prediction in FRP strengthened concrete bridge girders," European Journal of Advances in Engineering and Technology, vol. 2, no. 3, pp. 59-68, 2015.

[9] D. Bruno, F. Greco, S. L. Feudo, and P. N. Blasi, "Multi-layer modeling of edge debonding in strengthened beams using interface stresses and fracture energies," Engineering Structures, vol. 109, pp. 26-42, 2016.

[10] O. Rabinovitch, "Debonding analysis of fiber-reinforcedpolymer strengthened beams: cohesive zone modeling versus a linear elastic fracture mechanics approach," Engineering Fracture Mechanics, vol. 75, no. 10, pp. 2842-2859, 2008.

[11] J. G. Teng, J. W. Zhang, and S. T. Smith, "Interfacial stresses in reinforced concrete beams bonded with a soffit plate: A Finite Element Study," Construction and Building Materials, vol. 16, no. 1, pp. 1-14, 2002.

[12] M. J. Mathews and S. R. Swanson, "Characterization of the interlaminar fracture toughness of a laminated carbon/epoxy composite," Composites Science and Technology, vol. 67, no. 7-8, pp. 1489-1498, 2007.

[13] K. J. Willam and E. P. Warnke, "Constitutive model for triaxial behavior of concrete," in Proceedings of the Seminar on Concrete Structures Subjected to Triaxial Stresses, International Association of Bridge and Structural Engineering Conference, Bergamo, Italy, 1974.

[14] J. G. MacGregor, Reinforced Concrete Mechanics and Design, Prentice Hall, Englewood Cliffs, NJ, USA, 1992. 
[15] A. J. Wolanski, Flexural behavior of reinforced and prestressed concrete beams using finite element analysis [M.S. thesis], Marquette University, Milwaukee, Wis, USA, 2004.

[16] American Concrete Institute (ACI), "Building code requirements for structural concrete," ACI 318-14, American Concrete Institute (ACI), Farmington Hills, Mich, USA, 2014.

[17] AASHTO (American Association of State Highway and Transportation Officials), LRFD Bridge Design Specifications, AASHTO (American Association of State Highway and Transportation Officials), Washington, DC, USA, 7th edition, 2014. 


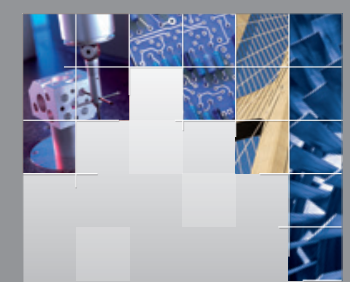

\section{Enfincering}
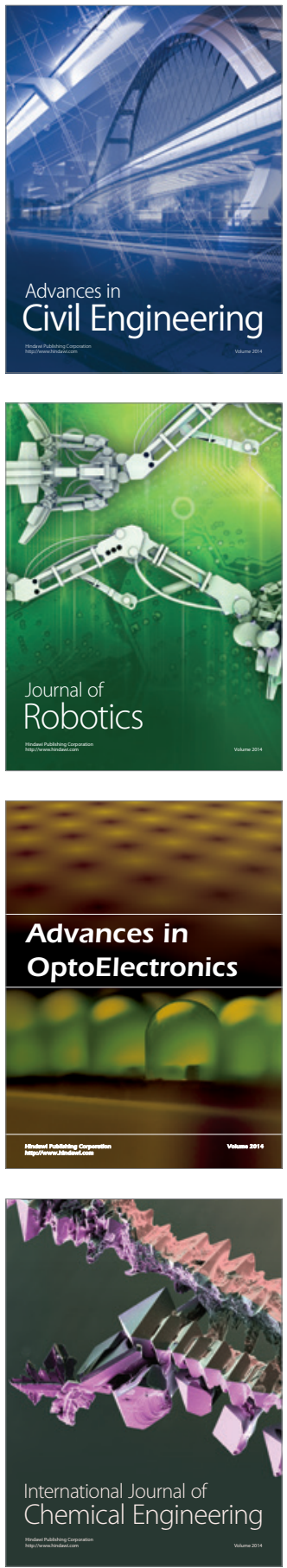

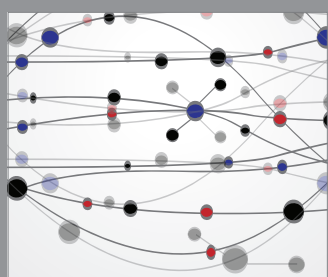

The Scientific World Journal

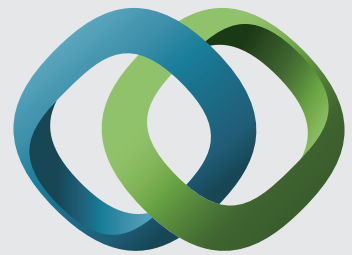

\section{Hindawi}

Submit your manuscripts at

http://www.hindawi.com
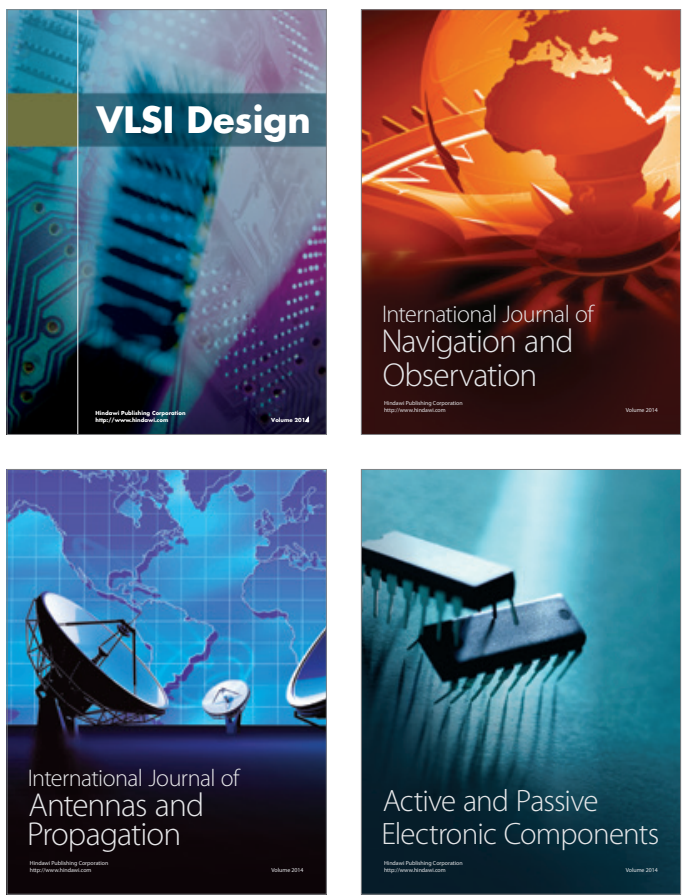
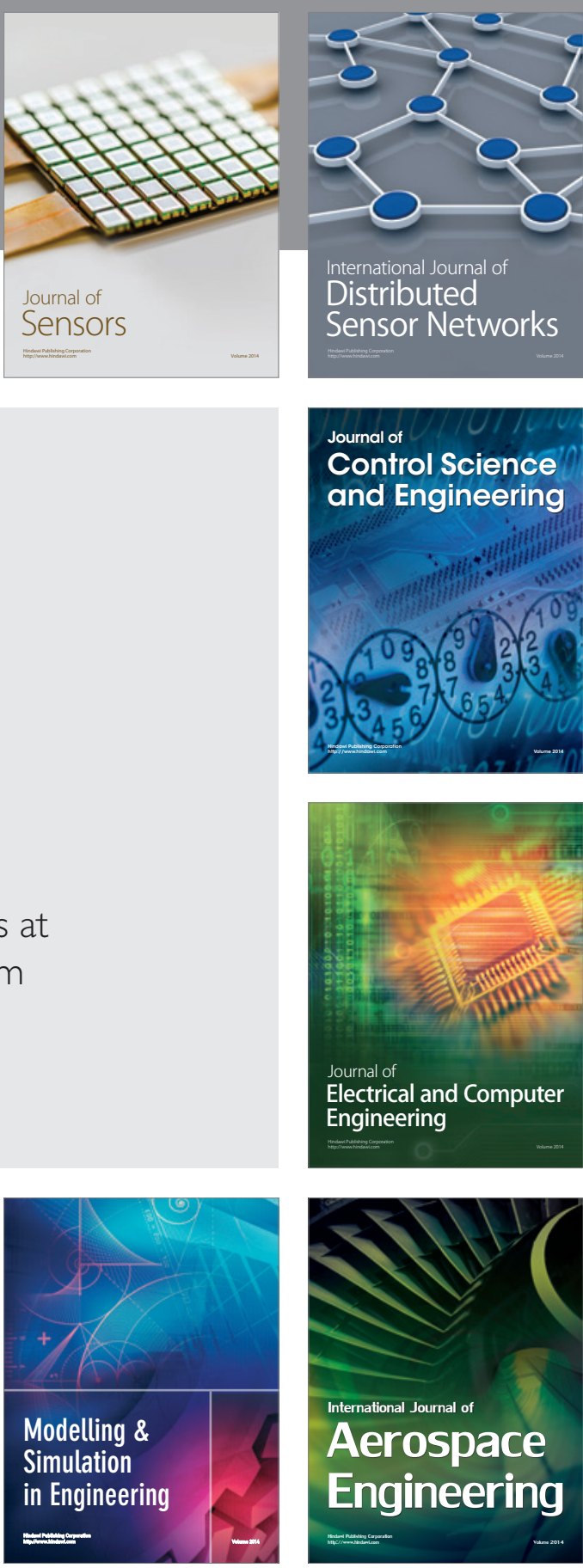

International Journal of

Distributed

Sensor Networks

Journal of

Control Science

and Engineering
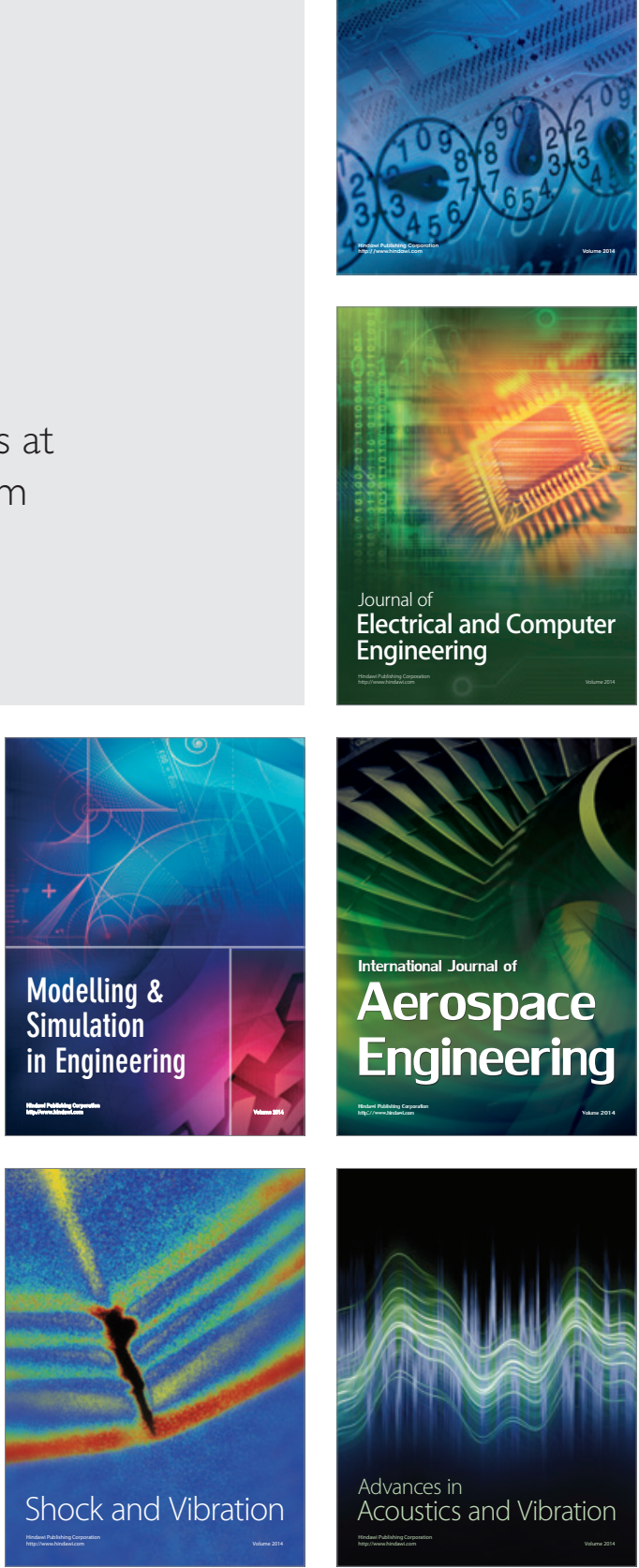